\title{
Correlation between Handgrip Strength, Mobilization Function, Physical Activity Level, and Muscle Mass in Community-Dwelling Elderly in Bandung, West Java Province, Indonesia
}

\author{
Sari Sekarsari, ${ }^{1}$ Vitriana, ${ }^{2}$ Irma Ruslina Defi ${ }^{2}$ \\ ${ }^{1}$ Rehabilitation Medicine Instalation, West Java Province Mental Hospital \\ ${ }^{2}$ Department of Physical Medicine and Rehabilitation, Faculty of Medicine, Universitas Padjajaran-Dr. Hasan \\ Sadikin General Hospital, Bandung
}

$\begin{array}{ll}\text { Abstract } & \text { Objective: To investigate correlation between handgrip strength, mobilization } \\ & \text { function, and physical activity level (PAL), and muscle mass in community- } \\ \text { dwelling Indonesian elderly. } & \\ & \text { Methods: This was a cross-sectional study 193 subjects aged 60-90 years. } \\ & \text { Handgrip strength was measured using handgrip dynamometer while the } \\ & \text { mobilization function was assessed by performing gait speed test. Global } \\ & \text { Physical Activity Questionnaire (GPAQ) was used to assess the participant's } \\ & \text { PAL and Bio Impedance Analyzer was used to measure the participant's } \\ & \text { muscle mass based on skeletal mass index. } \\ & \text { Results: Significant positive correlations were discovered between handgrip } \\ & \text { strength and walking speed (rs. 0.501; p<0.001), PAL (rs. 0.153; p=0.003), } \\ & \text { and muscle mass (rs. 0,452; p<0.001). } \\ \text { Received: } & \begin{array}{l}\text { Conclusions: Stronger handgrip determines greater mobilization function, } \\ \text { physical activity level, and bigger muscle mass in community-dwelling }\end{array} \\ \text { July 10, 2017 } & \text { Indonesian elderly. } \\ \text { Revised: } & \text { Keywords: Gait speed, handgrip strength, muscle mass, physical activity } \\ \text { August 8, 2017 } & \text { pISSN: 2302-1381; eISSN: 2338-4506; http://doi.org/10.15850/ijihs.v6n1.1047 } \\ \text { Accepted: } & \text { IJIHS. 2018;6(1):1-5 } \\ \text { February 19, 2018 }\end{array}$

\section{Introduction}

One of the triggers of decrease in muscle mass and strength is aging. A decrease of $1-2 \%$ per year is usually seen after the age of 50 years old. ${ }^{1}$ Longitudinal and interventional studies reveal that muscle atrophy slightly contributes to the reduction in muscle strength. ${ }^{2}$ Lower extremity muscle strength is regarded as one of mobilization predictors. Decreased lower extremity muscle strength leads to limitation of mobilization function which becomes a major factor in reduced physical and functional performance among elderly. ${ }^{3}$

A previous study stated that the handgrip strength is an indicator of the overall muscle

\footnotetext{
Correspondence:

Sari Sekarsari, Rehabilitation Medicine Instalation, West Java Province Mental Hospital

Jl. Kolonel Masturi KM 07, Cipada, Cisarua, Kabupaten Bandung Barat, West Java, Indonesia e-mail: sarisekarsari@gmail.com
}

strength. Handgrip strength was found to be correlated with lower extremity strength. ${ }^{4}$ Various factors could influence the handgrip strength value, which maybe different among countries. ${ }^{5}$ Data related to handgrip strength in Indonesian elderly are still scarce. Therefore, this study aimed to examine the correlation between handgrip strength and mobilization function, physical activity level (PAL), and muscle mass in Indonesian elderly.

\section{Methods}

This was a cross-sectional study conducted in Bandung from September 2015 to March 2016. The subjects in the study were communitydwelling elderly who visited public health centers in three subdistricts in Bandung City, Indonesia i.e. Batununggal, Cibeunying, and Coblong. Consecutive sampling was used in this study. 
Inclusion criteria in the study were elderly aged 60-90 years old, had Mini Mental Status Examination (MMSE) score of $\geq 24$, able to walk independently both indoors and outdoors with or without a walker, signing the approval form after informed consent, and not staying at any retirement home. Subjects were excluded from this study if subject had musculoskeletal and neuromuscular disorders that prevent them to walk independently; used artificial metal implant including the use of cardiac pacemaker that may interfere with the accuracy of the assessment; suffered from any malignancy, chronic inflammation, congestive cardiomyopathy, as well as kidney disorders which caused muscle mass decrease; and deformity and weakness in upper extremity that influence the handgrip. This study was approved through the ethical clearance by the Health Research Ethic Committee, Faculty of Medicine, Universitas Padjadjaran.

Handgrip strength is the maximum muscle strength produced by the contraction of the hand muscle during handgrip. The handgrip strength measurement was performed using Lafayette hand dynamometer in a standing position. The measurement results were then interpreted in kilogram (kg). ${ }^{6}$

Mobilization function physical performance assessment was conducted by performing gait speed test. At the beginning of the test, the subjects stood behind the starting line. The subjects were instructed to walk a 11-meter distance with possible speed and stop after entering the finish line. The subjects were previously informed about the possibility of experiencing problems such as shortness of breath and weakness while walking. If problems were found when performing the test, the subjects were allowed to slow the steps or stop. The results were the gait speed taken from 5 to 11 meter (the last 6 meter). Therefore, the results were interpreted into meter/second. ${ }^{7}$

Physical activities are considered as all body movements performed by skeletal muscles that requires the expenditure of energy, such as working, playing, and traveling. ${ }^{8}$ The physical activity level in this study was assessed using Global Physical Activity Questionnaire (GPAQ) standardized by the World Health Organition (WHO) which had been validated or translated into Indonesian. The questionnaire consists of 16 questions related to the intensity of the physical activities done by the subjects in three conditions i.e. physical activity while working, moving from a place to another place, recreating, and sedentary behavior. The data were assessed by using GPAQ Analysis Guide and metabolic equivalent per minute (METminutes) and the results were calculated every week and classified based on age. High activity duration time coefficient equals to MET energy of 8 , while moderate activity duration time coefficient equals to MET energy of 4 . High PAL were those who reached minimum 1500 MET-times in 3 days per week or 7 days or more doing walking combination of moderate and high PALs reaching minimum 3000 MET-minutes per week. Moderate PAL typically found in those who performed 3 days or more high PAL minimum 20 minutes per day or 5 days or more doing moderate PAL or walking minimum 30 minutes per day or 5 days or more doing combination of walking, moderate and high PALs reaching minimum 600 MET-minutes per week. Low PAL are those who did not meet moderate and high PALs criteria. Sedentary behavior was classified based on the total minutes per day in sitting, traveling using a vehicle, watching television, reading, playing cards, and sleeping without any time estimation. ${ }^{8}$ In addition, the PAL assessment was performed through selfreported questionnaire.

Data on the appendicular skeletal muscle mass index (ASMI) were collected by using Bio Impedance Analyzer (BIA/Tanita BC601, Tanita Corp, Tokyo, Japan). In the study, the formula used to measure the muscle mass is the appendicular skeletal muscle mass index= ASMI/(height) ${ }^{2}$. The data obtained would be interpreted in kilogram $\left(\mathrm{kg} / \mathrm{m}^{2}\right){ }^{7}$

Shapiro Wilks test was used to investigate the normality of data distribution. Correlational analysis was used to examine the correlation between handgrip strength, walking speed, PAL, and muscle mass using Pearson or Rank Spearman correlation test depending on data distribution.

\section{Results}

Of 203 participants, only 193 subjects, which consisted of 130 females and 63 males, met the inclusion criteria. Characteristics of subjects were described in details (Table 1). The mean age of the study subjects was $68.14 \pm 7.2$ years for female and 70.84 years for male, with half of the study subjects had moderate PAL.

The average ASMI value for female subjects was lower than for male subjects (6.9 vs. 8.12 $\mathrm{kg} / \mathrm{m}^{2}$ ), while the average gait speed value was higher in males than in females ( 0.68 vs. $0.57 \mathrm{~m} /$ second). Male handgrip strength was 
Table 1 Subject Characteristics

\begin{tabular}{lccc}
\hline \multicolumn{1}{c}{ Characteristics } & & Female (n=130) & Male (n=63) \\
\hline Age (years)* & $\leq 70$ & $83(63.8 \%)$ & $32(50.8 \%)$ \\
& $71-80$ & $40(30.7 \%)$ & $24(38.1 \%)$ \\
& $81-90$ & $7(5.4 \%)$ & $7(11.1 \%)$ \\
Physical activity level* & Mean (SD) & $68.14(7.2)$ & $70.84(7.69)$ \\
& Low & $35(26.9 \%)$ & $15(23.8 \%)$ \\
ASMI (kg/m²) & Hoderate & $59(45.4 \%)$ & $32(50.8 \%)$ \\
Gait speed* (m/second) & Mean (SD) & $36(27.7 \%)$ & $16(25.4 \%)$ \\
Handgrip strength* (kg) & Mean (SD) & $6.90(1.09)$ & $8.12(1.13)$ \\
\hline
\end{tabular}

Notes: *Distribution is not normal by Shapiro Wilks normality test

ASMI= appendicular skeletal muscle mass Index; BMI= body mass index

stronger than female handgrip strength (25 vs. $14 \mathrm{~kg}$ ). The correlations between the handgrip strength, walking speed, physical activity level, and muscle mass were considered statistically significant, albeit not strong (Table 2).

\section{Discussion}

The number of female subjects in this study was higher. This is consistent with the data that is published by the Ministry of Health of Republic Indonesia in 2014 stating that the prevalence of life after middle age of females is higher than males. ${ }^{9}$ The higher life expectancy for females is influenced by the physicological indulgent condition and the ability to control emotion and feelings, describing that females are more prepared to face problems than males. The ability to adapt to various aspects of life becomes the main reason that female elderly can show satisfaction in any condition in life. ${ }^{10}$ Another possibility is that women are more likely to participate in community activities than men; hence, women visit public health care more than men. ${ }^{11}$

In this study, the average handgrip strength value in males $(25 \mathrm{~kg})$ is higher than females $(14 \mathrm{~kg})$. The values gained in this study are lower than those of a similiar study conducted on elderly aged $>65$ years old in Korea (27.7 $\mathrm{kg}$ in males, $14.9 \mathrm{~kg}$ in females) and also when compared with the results of a study conducted on elderly $>60$ years old in Germany ( $45 \mathrm{~kg}$ in males, $26 \mathrm{~kg}$ in females). ${ }^{12}$ The difference in handgrip strength is caused by ethnicityrelated anthropometric differences as well as different muscle characteristics. Africans and Americans have the highest skeletal muscle mass values, followed by White, Hispanic, and Asian people. ${ }^{13}$

A significant correlation between handgrip strength and gait speed was ascertained in this study. An earlier study has shown a correlation between upper extremity muscle mass and handgrip strength as well as between lower extremity muscle mass and gait speed. ${ }^{14}$ This is also supported by a study which reported that handgrip strength in elderly correlates with hand flexion, knee extensor, and trunk flexion and extension that play a role in walking; therefore, the correlation between handgrip strength and gait speed can be explained. ${ }^{15}$

\begin{tabular}{|c|c|c|}
\hline Correlation & rs* & p Value \\
\hline $\begin{array}{l}\text { Handgrip strength and } \\
\text { ASMI }\end{array}$ & 0.4516 & $<0.001^{* *}$ \\
\hline $\begin{array}{l}\text { Handgrip strength and } \\
\text { physical activity level }\end{array}$ & 0.1527 & $0.0340^{* *}$ \\
\hline $\begin{array}{l}\text { Handgrip strength and } \\
\text { gait speed }\end{array}$ & 0.501 & $<0.001^{* *}$ \\
\hline Minimum & 7 & 19 \\
\hline Maximum & 17 & 39 \\
\hline
\end{tabular}


Gait speed is associated with age, strength, physical activity, and cardiovascular diseases. ${ }^{16}$ It is also used as an indicator of the physical performance mobilization in elderly because walking requires energy, movement control, and support from particular systems in the body including the cardiovascular, neural, and musculoskeletal systems. ${ }^{15}$

In this study, half of the total number of subjects have moderate PAL. A study using GPAQ on PAL among > 65 years old elderly in Czech Republic has revealed that $52.8 \%$ of the subjects have a low PAL while $18.9 \%$ and $28.3 \%$ of the subjects have a moderate and high PAL scores, respectively. ${ }^{17}$ The results in this study are higher when compared to the previous study. ${ }^{17}$ This might be due to the fact that the age range of the subjects in this study is younger than the subjects in the study conducted in Czech Republic (60-90 vs 65-90 years).

The average ASMI scores are $6.9 \mathrm{~kg} / \mathrm{m}^{2}$ and $8.12 \mathrm{~kg} / \mathrm{m}^{2}$ for females and males, respectively, which is in line with the result of a previous study stating that male muscle mass is higher than females in the later stages of life. This is associated with the presence of testosterone hormone. Meanwhile, the fat composition in females is higher than in males. ${ }^{18}$

Acorrelation between the handgrip strength and ASMI is found. Skeletal muscles play a role in voluntary movements. In elderly, decrease in muscle mass occurs due to the decrease in muscle fiber, motor unit and muscle fiber size. Decrease in muscle fiber becomes a trigger for a decrease in muscle strength. Cellular, neural, and metabolical factors also play a role in the reduction of the muscle strength. ${ }^{1,19}$

A careful interpretation on the results of this study is needed due to its cross-sectional design and the fact that it only included local citizens of Bandung, making it less likely to represent Indonesian elderly. With that in mind, it can be concluded that stronger handgrip may determine greater mobilization function, physical activity level, and bigger muscle mass in community-dwelling Indonesian elderly.

\section{References}

1. Keller K, Engelhardt M. Strength and muscle mass loss with aging process age and strength loss. Muscles Ligaments Tendons J. 2013;3(4): 346-50.

2. Delmonico M, Harris T. Longitudinal study of muscle strength, quality and adipose tissue infiltration. Am J Clin Nutr. 2008;90(6): 157985.

3. Liu LK, Lee WJ, Liu CL, Chen LY, Lin MH, Pneg LN, et al. Age-related skeletal muscle mass loss and physical performance in Taiwan: implications to diagnostic strategy of sarcopenia in Asia. Geriatr Gerontol Int. 2013;13(4):964-71.

4. Wang CY, Olson SL, Protas EJ. Lower extremity muscle performance associated with community ambulation in elderly fallers. Asian J Gerontol Geriatr. 2009;4(1):52-7.

5. Sirajudeen MH, Shah U, Pillai PS, Mohasin N, Shantaram M. Correlation between grip strength and physical factors in men. Int J Health Rehabil Sci. 2012;1(2):58-63.

6. El-Sais WM, Mohammad WS. Influence of different testing postures on hand grip strength. Eur Sci J. 2014;10(36):290-301.

7. Chen LK, Liu LK, Woo J, Assantachai P, Auyeung TW, Bahyah KS, et al. Sarcopenia in Asia: consensus report of the Asian working

group for sarcopenia. J Am Med Dir Assoc. 2014;15(2):95-101.

8. World Health Organization. Global physical activity surveillance. [cited 2015 July 6. Available form: http://www.who.int/chp/ steps/GPAQ/en/.

9. Yudianto, Budijanto D, Hardhana B, Soenardi T. Profil Kesehatan Indonesia 2014. Jakarta: Kementrian Kesehatan Republik Indonesia; 2015.

10. Yuliati A, Baroya N, Ririanty M. Perbedaan kualitas hidup lansia yang tinggal di komunitas dengan di pelayanan sosial lanjut usia. Pustaka Kesehatan. 2014;2(1)87-94.

11. Prachuabmoh V. Preparation for old age and social participation of present and future old persons in Thailand: gender difference. In: Devasahayam WT, editor. Gender and ageing: Southeast Asian perspectives. Singapore: ISEAS; 2014. p. 115-7.

12. Lee JE, Kim KW, Paik N, Jang H, Chang CB, et al. Evaluation of factors influencing grip strength in elderly Koreans. J Bone Metab. 2012;19(2):103-10.

13. Silva A, Shen W, Heo M, Gallagher D, Wang Z, Sardina LB, et al. Ethnicity-related skeletal muscle differences across the lifespan. Am J 
Hum Biol. 2010;22(1):76-82.

14. Wang CY, Olson SL, Protas EJ. Lower extremity muscle performance associated with community ambulation in elderly fallers. Asian J Gerontol Geriatr. 2009;4(1):52-7.

15. Deeg D, Bouter L. Skeletal muscle mass and muscle strength in relation to lower extremity performance in older men and women. J Am Geriatr Soc. 2000;49(4):380-7.

16. Busch T, Duarte $Y$, Nunes D, Lebrao $M$, Naslavsky $\mathrm{M}$, Rodrigues $\mathrm{A}$, et al. Factors associated with lower gait speed among the elderly living in a developing country: a crosssectional population-based study. BMC Geriatr [serial on the internet]. 2015 Apr [cited 2016 Mar 7];15(35):[about 9p.]. Available from: https://bmcgeriatr.biomedcentral.com/ articles/10.1186/s12877-015-0031-2.

17. Hamrik Z, Sigmundora D, Sigmund E. Physical activity and sedentary behavior in Czech adults. Eur J Sport Sci. 2014;14(2):193-8.

18. Bai HJ, Sun JQ, Chen M, Xu DF, Xie H, Yu ZW, et al. Age related decline in skeletal muscle mass and function among elderly men and women in Shanghai, China: a coss sectional study. Asia Pac J Clin Nutr. 2016;25(2)326-32.

19. Clark G, Kortebein P, Siebens H. Aging and rehabilitation. In: Fontera W, editor. Delisa's physical medicine and rehabilitation. Philadelphia: Lippincot Williams \& Wilkins; 2010. p. 1545-77. 